\title{
NUMERICAL AND ANALYTICAL STUDIES
}

\section{OF A SHAKER TEST SYSTEM FOR FATIGUE TESTING}

\author{
Philipp Renhart ${ }^{1}$, Igor Milošević ${ }^{1}$, Florian Grün ${ }^{1}$
}

1 Montanuniversität Leoben, Chair of Mechanical Engineering, Franz-Josef-Straße 18, 8700 Leoben, Austria. E-mail: philipp.renhart@unileoben.ac.at, igor.milosevic@unileoben.ac.at

\section{Introduction}

Conventional test rigs for fatigue testing (servo hydraulic, resonant test systems) are usually working up to $100 \mathrm{~Hz}$. For the characterization of VHCF (very high cycle fatigue) phenomena up to $10^{9}$ load changes should be proved, which leads to an exorbitant standard testing period. The desire for material testing at higher frequencies is obvious. In the design process of high frequency test devices, it is essential to have detailed knowledge of the resonant frequencies for the planned system. Finite-Element calculations are a relatively precise tool for frequency predictions tough they are time-consuming. The aim of this work is the development of a solid analytical calculation routine for resonant frequency identification. Resonant frequencies strongly depend on the stiffness of the system; therefore, the focus will be laid on this calculation. For the validation of the simplified calculation an existing testing machine [1] has been used.

\section{Experimental Setup}

Two accelerometers are mounted on the baseplate (control sensor) respectively on the mass (monitor sensor). Fig. 1 shows the experimental device for high frequency VHCF tests. Before the test the specimen is tightened to the base with a M20x1,5 thread. Afterwards the mass $(2,42 \mathrm{~kg})$ is loosely screwed onto the specimen and the guides are mounted. Lastly the mass is secured with a secondary bolt $(0,148 \mathrm{~kg})$ from the top face.

The performed sweep-test is mainly defined by the constant and absolute value of acceleration $\left(a_{\text {Base }}=10 \mathrm{~ms}^{-2}\right)$ respectively the frequency range. During a sweep-test the harmonic excitation frequency rises constant (sweep-rate) with time. Detailed test definitions are listed in Tab. 1.

Tab. 1. Test definition data of a single sweep- test.

\begin{tabular}{|c|c|c|c|}
\hline $\begin{array}{c}\text { Base- } \\
\text { acceleration } \\
{\left[\mathrm{m} / \mathrm{s}^{2}\right]}\end{array}$ & $\begin{array}{c}\text { Frequency- } \\
\text { Range } \\
{[\mathrm{Hz}]}\end{array}$ & $\begin{array}{c}\text { Sweep- } \\
\text { Rate } \\
{[\mathrm{Hz} / \mathrm{s}]}\end{array}$ & $\begin{array}{c}\text { Applied- } \\
\text { Mass } \\
{[\mathrm{kg}]}\end{array}$ \\
\hline
\end{tabular}

\begin{tabular}{l|l}
10 & $500-1200$
\end{tabular}

2,57

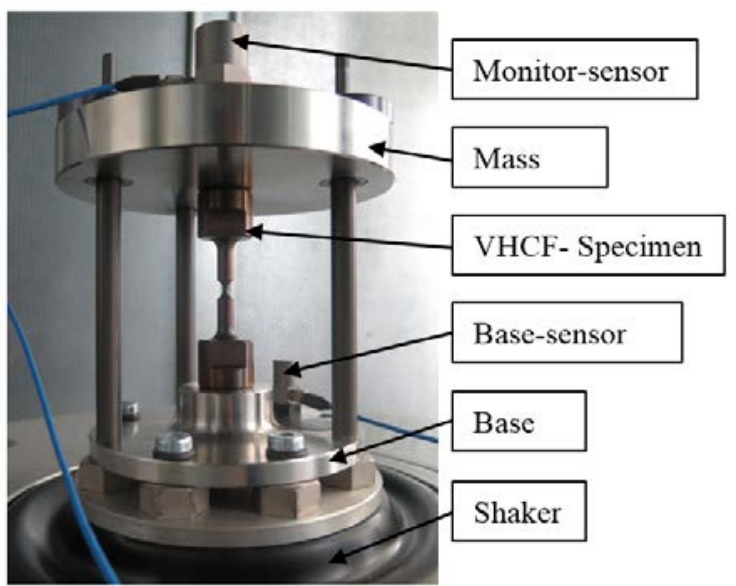

Fig. 1. Instrumented experimental setup for VHCF tests.

During the sweep-test the acceleration of the mass is measured to obtain the response of excitation. In the subsequent evaluation resonant frequency and damping ratio behavior can be identified.

\section{Resonant Frequency Determination}

\subsection{Analytical approach}

The testing system can be simplified to a SDOF (single degree of freedom) oscillator with a pointmass $m$ and a linear spring (specimen and base) with a constant stiffness $c$. The differential equation of a damped SDOF system with viscous damping system is:

$$
m \ddot{x}+d \dot{x}+c x=0 .
$$

For these SDOF system the un-damped resonant frequency $f_{N}$ can be described by Eq. (2)

$$
f_{N}=\frac{1}{2 \pi} \sqrt{\frac{c}{m}} .
$$

The damped resonant frequency $f_{D}$ is given by Eq. (3), whereby the fraction of critical damping equals $\xi=d / 4 m \pi f_{N}$ [2] 


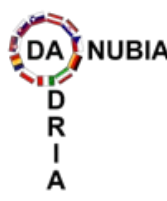

$$
f_{D}=f_{N} \sqrt{1-\xi^{2}}
$$

The value for viscous damping was taken from Yun's [3] work. With $d=0.016$ the fraction of critical damping $\xi$ can be neglected for frequency estimation. With a known mass only the stiffness has to be calculated. The basic approach is to determine the compliance $\delta$ (reciprocal of c) using the differential relation according to Eq. (4)

$$
d \delta=\frac{1}{E \cdot A(x)} d x .
$$

The specimen Fig. 2 is separated in single springs with cross-sections that can be analytically calculated. The total stiffness of multiple crosssections is determined by a serial-connection of individual springs.

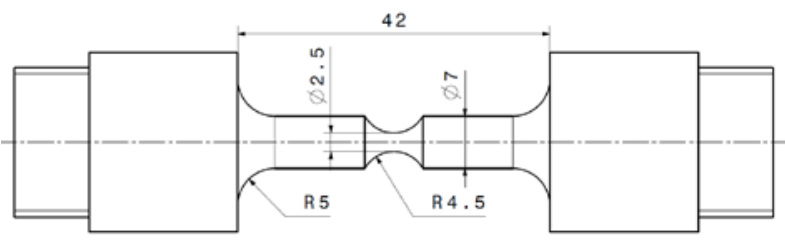

Fig. 2. Dimensions of the specimen.

The base can be seen as a rotationally symmetric plate. By applying Kirchhoff's plate theory [4] in Eq. (5) the central compliance $w_{\max }=$ $\delta$ is calculated analytically

$$
\begin{aligned}
& \Delta \Delta w=\frac{p(r, \varphi)}{K} \\
& \text { with } K=\frac{E h^{3}}{12\left(1-v^{2}\right)} .
\end{aligned}
$$

Lastly the deflection of the screws between the shaker and the base has been considered in the stiffness-calculation (parallel connection). The determined resonant-frequency is $804.9 \mathrm{~Hz}$.

\subsection{Numerical Approach}

Resonant frequency estimations with FiniteElements were performed in ABAQUS 6.14 using a linear perturbation step (modal analysis). In a further step the sweep-test was virtually performed by using a harmonic excitation at the base with different excitation-frequencies (direct steady-state analysis). First all threaded connections in the 3D model were tightened in which the thread connections were implemented with a clearance contact condition. The numerically determined resonant-frequency is $796 \mathrm{~Hz}$. For the damping of the system Rayleigh-Damping was used.

\section{Validation}

In the experiment a resonant-frequency of $833 \mathrm{~Hz}$ has been detected. The error in the analytic solution is $28,1 \mathrm{~Hz}(-3,7 \%)$. The deviation in the numerical solution is $37 \mathrm{~Hz}(-4,4 \%)$. In Fig. 3 the result of the sweep-test and calculated tests are shown.

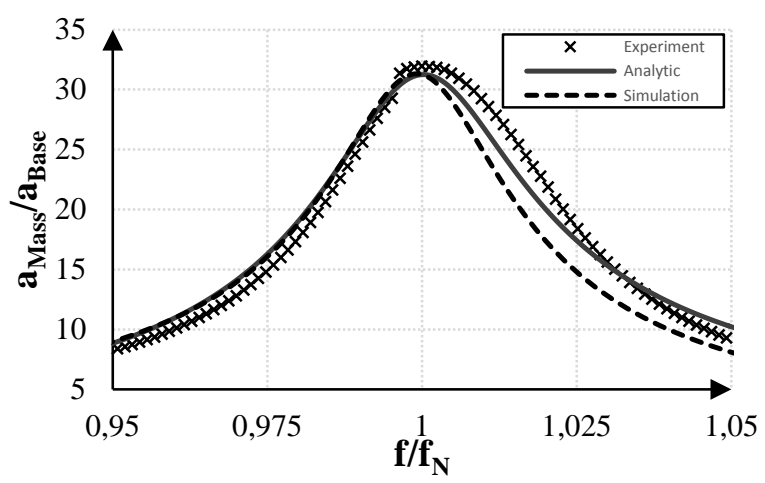

Fig. 3. Comparison of the experimental sweep-test and the analytically respectively numerically calculated response data (a....acceleration).

\section{Remarks}

- Analytic and numerical solutions are tolerably accurate, if comparatively soft connections (e.g. screws, plates) were considered.

- In subcritical $\left(f<f_{N}\right)$ acceleration response prediction a good accordance to the experiment has been observed.

- The frictional influence of the guides has not been studied so far. The focus in further studies will be laid on this and other dissipative effects.

\section{References}

[1] Milošević I., Renhart P., Validating a new high frequency testing method for martensitic high strength steels under tension/compression loading in the VHCF regime., International Journal of fatigue., 2017, In Press.

[2] Harris C.M., Piersol A.G., Shock and Vibration Handbook $5^{\text {th }}$ Edition, McGrawHill, New York, 2002

[3] Yun G.J., Development of a Closed-Loop High-Cycle Resonant Fatigue Testing System, 

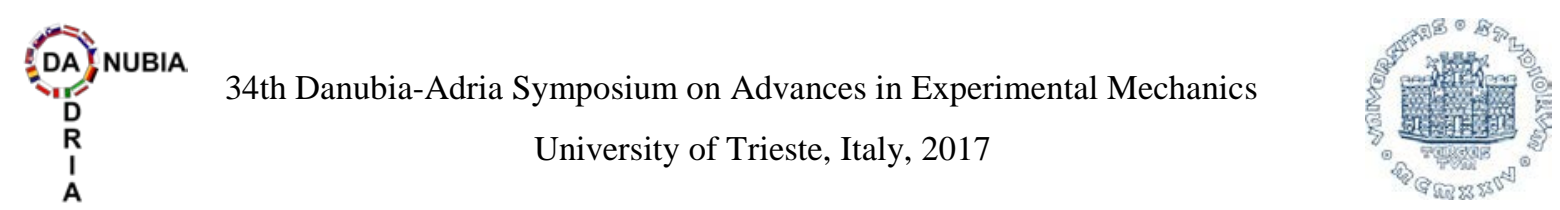

Experimental Mechanics 52, 2012. pp. 275288.

[4] Kirchhoff G., Vorlesungen über mathematische Physik, Teubner, Leipzig, 1876. 